\title{
Angular pregnancy: an under-recognised entity presenting with retained placenta
}

\author{
Sarita Rajbhar ${ }^{1}$, Minu Keshkar ${ }^{2 *}$ \\ ${ }^{1}$ Department of Obstetrics and Gynaecology, AIIMS, Raipur, Chhattisgarh, India \\ ${ }^{2}$ Department of Obstetrics and Gynaecology, Chhattisgarh Institute of Medical Sciences, Bilaspur, Chhattisgarh, India
}

Received: 10 May 2021

Accepted: 03 June 2021

\section{*Correspondence:}

Dr. Minu Keshkar,

E-mail: minu.keshkar@gmail.com

Copyright: $(\odot$ the author(s), publisher and licensee Medip Academy. This is an open-access article distributed under the terms of the Creative Commons Attribution Non-Commercial License, which permits unrestricted non-commercial use, distribution, and reproduction in any medium, provided the original work is properly cited.

\begin{abstract}
Retained placenta accounts for most of the cases of postpartum haemorrhage and occurs commonly due to contracted lower half of uterus and closed os, it can rarely also occur if it gets trapped at the cornua of the uterus due to angular implantation. A 26 year old P3L3 was got referred for retained placenta, she was diagnosed with angular pregnancy after laparotomy after manual removal failed, she was managed with hysterotomy. Angular pregnancy may lead to preterm delivery and trapping of the placenta.
\end{abstract}

Keywords: Angular pregnancy, Retained placenta, PPH, Preterm labour

\section{INTRODUCTION}

Angular pregnancy refers to a condition wherein the embryo is implanted in the lateral angle of the uterine cavity, medial to the uterine-tubal junction and round ligament. ${ }^{1}$ It was described for the first time in 1898 by American obstetrician Howard Kelly. Although being described centuries ago angular pregnancy is yet underrecognized. The entity is seldom described in textbooks and literature and often confused with interstitial and cornual pregnancy.

Retained placenta is a condition wherein all or part of placenta or membrane remains within the uterus during the third stage of labour, it may occur either due to failed separation of the placenta from the uterine wall or after separation it may get trapped because of closed os. Very rarely it may get trapped due to angular implantation of the placenta. Angular pregnancy may lead to many complications during the peripartum and during puerperium but there are deficiencies of literature for retained placenta occurring due to cornual or angular pregnancy, We herein reported such a case of retained placenta presenting after a preterm vaginal delivery at home resulting from angular implantation of placenta, the diagnosis could be made only at the time of laparotomy done for failed manual removal of placenta.

\section{CASE REPORT}

A 26 year P3L3 female presented to emergency services at night with a history of preterm vaginal delivery at 34 weeks of gestation at her home 12 hours back with retained placenta. Delivery was conducted by neighbours, when the placenta failed to deliver after 2 hours, she was taken to a nearby primary healthcare facility from where she was referred to our centre. She had a history of previous 2 vaginal delivery at her home. She had no proper antenatal check-up during this pregnancy. At presentation, she had a pulse rate of 94 beats/minute and blood pressure of $100 / 74$, she was anaemic with $\mathrm{Hb}$ of $8 \mathrm{gm} \%$. Per abdominal uterus was 22 weeks size with retained placenta 
and mild vaginal bleeding present. As the USG facility was not available at late hours of the night so she was planned for manual removal of the placenta under general anaesthesia after arranging adequate blood products. Manual removal of the placenta was unsuccessful as the margin of the placenta could not be reached and on bimanual palpation under anesthesia placenta seemed to be implemented in a sac-like structure at the left cornual region of the uterus. Suspecting uterine anomaly laparotomy was performed. Upon laparotomy, a $15 \times 10 \mathrm{~cm}$ sacculation was present in the left cornua. Overlying myometrium was thinned out and bluish colouration of the placenta can be appreciated from outside. An incision over the cornual region given and the placenta was removed manually without much difficulty. Residual bleeding was secured by ligating bilateral utero ovarian anastomosis. The uterus was repaired in two layers. She received two units of packed red blood cells. The postoperative period was uneventful and she was discharged on the fifth postoperative day.

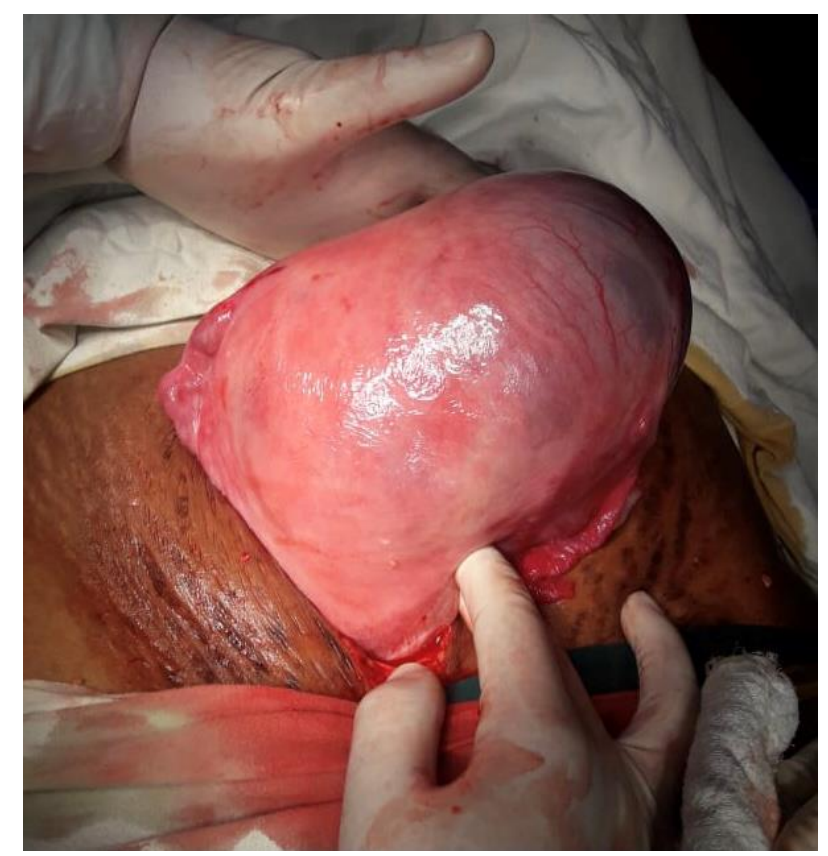

Figure 1: Showing bluish sacculation of placental implantation at the left cornua.

\section{DISCUSSION}

In angular pregnancy, the embryo is implanted in the lateral angle of the uterine cavity medial to the utero-tubal junction and round ligament. ${ }^{1}$ Whereas in interstitial pregnancy implantation occurs in the intramural portion of the fallopian tube and is a true ectopic pregnancy. Cornual pregnancy refers to a pregnancy in a rudimentary horn of a septate or bicornuate uterus. ${ }^{2,4}$ It is important to understand the difference between these entities as their risks, the potential for viability and management options differ and usually presents as an obstetric emergency.
Of the above three conditions only angular pregnancy and cornual pregnancy may continue till term, interstitial pregnancy usually ends between 12-16 weeks. Angular pregnancy is potentially dangerous and may lead to a myriad of obstetric complications during pregnancy and delivery like persistent uterine pain and bleeding, spontaneous abortion, preterm delivery and rarely retained placenta, placenta accreta and severe bleeding leading to hysterectomy. ${ }^{1,6}$

The diagnosis is difficult both antenatal and peripartum, especially if the presentation is late as in our case who presented with the retained placenta in an emergency. There is an increased risk of preterm delivery similar to our case and the uterine asymmetrical enlargement can be seen and palpated in a thin patient in an abdominal examination akin to our case. Further, there is an increased risk of placental abruption, growth restriction, an abnormal fetal position can be seen which was not seen in our case. ${ }^{6-}$

The incidence of retained placenta varies between 0.1 to $3.3 \%$ of vaginal deliveries. ${ }^{5}$ Only a few medical pieces of literature have reported a similar case of angular pregnancy with retained placenta requiring hysterotomy making it a very rare complication of angular pregnancy. ${ }^{2,3}$ This case highlighted the need to consider angular implantation of the placenta as a possible cause of retained placenta in a low-risk patient, as this is difficult to diagnose antenatally especially if the fetus is within the uterine cavity. The retained placenta may be the first presentation in such cases.

A similar condition may also arise in cases of cornual pregnancy in a septate uterus in such cases. ${ }^{9}$

This paper emphasised the risk associated with angular pregnancy which may get undetected till the third stage of labour complicating the presumed uncomplicated pregnancy culminating in a dreaded complication of retained placenta and $\mathrm{PPH}$.

If the angular pregnancy gets diagnosed during the antepartum, due caution should be exercised by monitoring diligently to prevent any further complications and preterm delivery.

If the factors predicting adverse outcomes in angular pregnancy are known, many dreaded complications can be prevented. It requires multicentre prospective or retrospective study to be done to come up with data sets that can predict the outcome with reasonable accuracy in cases of angular pregnancy.

\section{CONCLUSION}

Angular pregnancy can present with dreaded complications like retained placenta requiring laparotomy as in our case but is yet to be identified as a separate entity. It's diagnosis antenatally although is difficult but can 
prevent many complications and improve the perinatal outcome.

Funding: No funding sources Conflict of interest: None declared

Ethical approval: Not required

\section{REFERENCES}

1. Jansen RP, Elliott PM. Angular intrauterine pregnancy. Obstet Gynecol. 1981;58(2):167-75.

2. Arleo EK, DeFilippis EM. Cornual, interstitial, and angular pregnancies: clarifying the terms and a review of the literature. Clin Imaging. 2014;38(6):763-70.

3. Deckers EA, Stamm CA, Naake VL, Dunn TS, McFee JG. Hysterotomy for retained placenta in a term angular pregnancy: a case report. J Reproduct Med. 2000;4 (2):153-5.

4. Lancet M, Bin-Nun I, Kessler I. Angular and interstitial pregnancy. Int Surg. 1977;62(2):10709.
5. Weeks AD. The retained placenta. Best Pract Res Clin Obstet Gynaecol. 2008;22(6):1103-17.

6. Rankin MB, Dunning BSA, Arleo EK. Angular pregnancy: a review of cases reported in the past 80 years. Obstetr Gynaecol Case Rev. 2014;1:3.

7. Shekhar S, Verma S, Motey R, Kaushal R. Hysterotomy for retained placenta with imminent uterine rupture in a preterm angular pregnancy. Acta Obstetricia et Gynecologica Scandinavica. 2010;89(12):1615-6.

8. Triolo O, Mancuso A, Vivo AD, Falcone S. Term angular pregnancy with placenta accreta. a case report. Clinic Experiment Obstetr Gynecol. 2004;31(2):147-8.

9. Lee D, Johnson J. Hysterotomy for retained placenta in a septate uterus: a case report." Case Rep Obstetr Gynecol. 2012.

Cite this article as: Rajbhar S, Keshkar M. Angular pregnancy: an under-recognised entity presenting with retained placenta. Int J Reprod Contracept Obstet Gynecol 2021;10:2914-6. 